CLINICAL STUDY

\title{
Long-acting somatostatin analogues are an effective treatment for type 1 gastric carcinoid tumours
}

\author{
Simona Grozinsky-Glasberg ${ }^{1,4, *}$, Gregory Kaltsas ${ }^{5, *}$, Chamutal Gur ${ }^{6}$, Eyal Gal ${ }^{2}$, Dimitrios Thomas ${ }^{5}$, \\ Susana Fichman ${ }^{3}$, Krystallenia Alexandraki ${ }^{5}$, Dganit Barak ${ }^{6}$, Benjamin Glaser ${ }^{6}$, Ilan Shimon ${ }^{1,4}$ and David J Gross ${ }^{6}$ \\ Institutes of ${ }^{1}$ Endocrinology, ${ }^{2}$ Gastroenterology and ${ }^{3}$ Pathology, Rabin Medical Center, Beilinson Hospital, Petah Tikva, 49500 , Israel, ${ }^{4}$ Sackler Faculty of \\ Medicine, Tel Aviv, 69978, Israel, ${ }^{5}$ Department of Pathophysiology, National University of Athens, Athens, 10681, Greece and ${ }^{6}$ Endocrinology and \\ Metabolism Service, Department of Medicine, Hadassah-Hebrew University Medical Center, Jerusalem, 91120, Israel \\ (Correspondence should be addressed to S Grozinsky-Glasberg; Email: simonag@clalit.org.il) \\ *S Grozinsky-Glasberg and G Kaltsas contributed equally to this work
}

\begin{abstract}
Background: Gastric carcinoid tumours type 1 (GCA1) originate from hyperplastic enterochromaffinlike (ECL) cells secondary to hypergastrinaemia. Treatment with somatostatin analogues (SSA) might impede ECL-cell hyperplasia by suppressing gastrin secretion and/or by a direct anti-proliferative effect on ECL cells. We conducted a multicentre prospective study to assess the effects of long-acting SSA on hypergastrinaemia and ECL-cell proliferation in patients with GCA1.

Methods: We studied 15 patients with GCA1 treated with monthly long-acting release octreotide (LAR) (20-30 mg; $n=14$ ) or Lanreotide $90 \mathrm{mg}(n=1)$ for at least 6 months. Patients had serum gastrin and chromogranin A measurements performed and biopsies taken from both tumours and surrounding mucosa before, and every 6-12 months following treatment. Sections were immunostained for neuroendocrine markers. The cell proliferation index Ki-67, intensity of staining before and after treatment and the degree of gastric wall invasion were also assessed.

Results: All patients tolerated treatment well (mean follow-up of 18 months). In 11 patients (73\%), a complete disappearance of the tumours at 1 year of treatment was observed on endoscopy, while in three patients $(20 \%)$, the tumours decreased significantly in number and size. Gastrin levels normalized in $25 \%$ of patients, and were reduced by more than $80 \%$ in the remaining $75 \%$.

Conclusions: Treatment with SSAs in GCA1 leads to a substantial tumour load reduction, with a concomitant decrease of serum gastrin levels. Our data indicate an important anti-proliferative effect of SSA on ECL cells, providing clinical benefit and obviating, at least temporarily, the need for invasive therapies for GCA1.
\end{abstract}

European Journal of Endocrinology 159 475-482

\section{Introduction}

Gastric carcinoids (GCs) are endocrine tumours of the gastric mucosa that originate from enterochromaffinlike (ECL) cells (1). These tumours are divided into three distinct types: the majority $(\sim 75 \%)$ is type 1 GCA1, associated with chronic atrophic gastritis; type 2 (GCA2; $\sim 5-10 \%$ ) is associated with the ZollingerEllison syndrome and occur almost exclusively in the context of multiple endocrine neoplasia type 1 . Both type 1 and type 2 GCs are well-differentiated tumours related to hypergastrinaemia, and have an overall excellent prognosis. By contrast, type 3 GCs (15-25\%) are not related to hypergastrinaemia and follow an aggressive course (1-4).

Almost all type 1 GCs (ECLomas) are non-functioning tumours, typically discovered during upper gastrointestinal (GI) track endoscopy performed for either non specific symptoms (nausea, vomiting and abdominal pain or dyspepsia) (5), and/or during investigation of anaemia (6). Very occasionally, (less than 1\%), patients may complain of flushing and present with the 'atypical carcinoid syndrome' $(7,8)$. Type 1 GCs occur more frequently in women in the fifth and seventh decades $(9,10)$. However, with more extensive use of endoscopy, particularly in patients with other autoimmune diseases, the age at diagnosis may be younger $(11,12)$. In addition, in cases of pernicious anaemia (PA)-induced atrophic gastritis, areas of intestinal metaplasia within the gastric mucosa can develop increasing further the risk for malignancy (13).

Traditionally, GCA1s are endoscopically or surgically removed, depending on the number, appearance and size of the tumours $(14,15)$. Antrectomy, with surgical excision of the majority of the $G$ cells, is thought to facilitate regression of these tumours by removing the source of excessive gastrin secretion; however, the longterm benefits of antrectomy still remain uncertain 
(2, 16). Although proton pump inhibitors (PPIs) are effective in reducing hypergastrinaemia-induced gastric acid hypersecretion in GCA2 (17), they do not affect ECL-cell hyperplasia, therefore their role in GCA1 is limited (11). Moreover, in selected cases, significant reduction of hypergastrinaemia did not prevent development of ECL carcinoid (18), suggesting that, in addition to hypergastrinaemia, other pathogenic or genetic factors may be involved.

Over the last few years, somatostatin analogues (SSAs) have been used in the treatment of patients with either GCA1 or GCA2 (11), based on their capability to inhibit gastrin release from the $\mathrm{G}$ cells and thus reduce the ECLcell hyperplasia (19-22). Morphometric studies demonstrated that, while antrectomy specifically decreased the volume of ECL cells versus the total volume of endocrine cells, octreotide reduced the overall endocrine cell volume $(19,23)$. Although the number of treated patients is small, it has been suggested that SSA may exert important antiproliferative effects either directly, by inhibiting ECL-cells proliferation, or indirectly through suppression of gastrin hypersecretion (24).

We conducted a multicentre prospective study in order to assess the effects of long-acting SSA on excessive gastrin secretion, and subsequent ECL-cell growth in patients with GCA1. We also studied the ability of these drugs to induce regression of macroscopically visible tumours and concomitant intestinal metaplasia in treated patients.

\section{Materials and methods}

Fifteen patients with GCs type 1 diagnosed and treated in three different centres for at least a 6-month period were studied. Information on clinical presentation, biochemical profile, radiological assessment, histopathological findings and extent of the disease (using the recently introduced tumour, lymph nodes, metastases (TNM) classification) (25) were recorded. In addition, the application of other therapeutic modalities including surgery, and long-term outcome of these tumours were also recorded. Patients were assessed before the initiation of treatment, and thereafter at 6-month intervals both clinically, biochemically, endoscopically and histopathologically according to a uniform protocol (see below). Fourteen patients were treated with octreotide LAR (Novartis) at a monthly dosage of $20 \mathrm{mg}$ or $30 \mathrm{mg}$, depending on the symptomatic, biochemical and endoscopic response, while a patient received Somatuline Autogel (Ipsen, Paris, France) at a monthly dosage of $90 \mathrm{mg}$, due to intolerance to octreotide LAR.

\section{Clinical assessment}

In order to define symptomatic response, patients were questioned for the presence of specific symptoms such as abdominal pain, nausea, vomiting and dyspepsia (5).
In the absence of any symptoms, the reason for endoscopy was recorded particularly whether patients were investigated for anaemia either macrocytic or due to iron deficiency $(5,9)$. The presence of other autoimmune disorders in association with PA and the presence of carcinoid tumours or GI malignancies in other family members were also recorded.

\section{Biochemical evaluation}

All patients underwent a complete biochemical assessment. Pernicious anaemia was defined as low serum vitamin $B_{12}$ levels (normal range $180-670 \mathrm{pmol} / \mathrm{l}$ ) and at least one positive antibody titre against parietal cells, intrinsic factor and proton pump antigen. Serum gastrin and chromogranin A ( $\mathrm{CgA}$ ) were measured the morning before treatment with SSA after an overnight fast, and thereafter at regular intervals (3-6 months) during the study period. One patient was treated with PPIs preceding the beginning of the study due to suspected Barrett's oesophagus; the same patient was also on aspirin therapy due to a transient ischaemic event (Table 2, patient number 6 ). When previously used, PPIs were discontinued at least 6 weeks before blood samples were taken. Serum gastrin and $\mathrm{CgA}$ were measured using commercially available radioimmunoassay kits: DiaSorin, Stillwater, MN 55082-0285, USA, using a normal reference range of 40-108 mU/l for gastrin, and CGA-RIACT, Cisbio International, Bagnols-Ceze, France, using a normal reference range of $19.4-98.1 \mathrm{ng} / \mathrm{ml}$ for $\mathrm{CgA}$.

\section{Radiological assessment}

All patients underwent ${ }^{111}$ In-pentetreotide scintigraphy (Octreoscan) before the initiation of therapy. Ten patients also underwent computerized tomography (CT) of the abdomen to exclude the presence of distant metastases.

\section{Endoscopic and histopathological assessment}

All patients underwent upper GI endoscopy and endoscopic ultrasonography (EUS). Upper GI endoscopy with multiple biopsies in the antrum, body and fundus was performed and the 'dominant' lesions were removed if possible. EUS was performed to evaluate the extension of the lesions and exclude invasion of the muscularis wall, regional lymph node and/or visible metastases. Biopsies from both the tumours, if not completely resected, and surrounding mucosa in the antrum, body and fundus of the stomach were performed every 6 months during treatment. Sections were immunostained for chromogranin, neuron specific enolase (NSE), synaptophysin (SYP) and the Ki-67 proliferative index using the mindbomb homolog (Drosophila) (MIB-I) antibody. The diagnosis of carcinoid tumours was confirmed morphologically during endoscopy together with a positive immunocytochemical staining for NSE, SYP and/or chromogranin. 


\section{Evaluation of response to treatment}

In all cases, the disease response was defined using established World Health Organization (WHO) criteria, as follows: 1) complete response (complete regression of all clinical, radiological and hormonal evidence of the tumour); 2) partial response (a 50\% or greater reduction in all measurable tumour, clinical symptoms and hormonal levels, with no appearance of new lesions); 3) stable disease (less than $50 \%$ reduction or no greater than $25 \%$ increase in tumour size, clinical symptoms and hormonal measurements) and 4) tumour progression (appearance of new lesions, or an increase of $25 \%$ or more in tumour size, and clinical/hormonal deterioration) (12).

Patients were considered in remission if symptoms disappeared, gastrin and $\mathrm{CgA}$ levels were substantially reduced or returned to normal range and if there was no evidence of residual disease following treatment with SSAs. When a lesion was removed endoscopically prior to the initiation of therapy with SSAs, response to treatment was evaluated in the remaining lesions. The study was approved by the local institutional ethical committees and informed consent was obtained from all patients.

\section{Statistical analysis}

Results were expressed as mean \pm s.D. Differences in variables were analyzed by the $\chi^{2}$ test and Student's $t$-test using the SigmaStat 2.03 computerized program (Systat Software Inc., Point Richmond, CA, USA). $P<0.05$ was considered significant.

\section{Results}

The clinical characteristics of all patients included in the study are shown in Table 1. The cohort included 2 men and 13 women with a mean age of 53.9 years. The mean duration of follow-up was 18 months (range 6-48 months). Other autoimmune diseases (such as Hashimoto's thyroiditis, Graves' disease, Sjögren's syndrome or Addison's disease) were diagnosed in ten patients (67\%). In two patients $(13 \%)$ there was a positive first-degree relative family history of GC tumours.

Table 1 Demographic and clinical characteristics of the patients included in the study.

\begin{tabular}{lc}
\hline Characteristics & All patients $(n=15, \%)$ \\
\hline Age (years), mean \pm s.D. & $53.9 \pm 8.67$ \\
Male/female, $n$ & $2 / 13$ \\
Caucasians & $93 \%$ \\
Size of primary tumour $(\mathrm{mm})$, mean \pm s.D. & $9.10 \pm 9.7$ \\
Symptomatic, $(\%)$ & $13(87 \%)$ \\
Atrophic gastritis $(\%)$ & $15(100 \%)$ \\
Other autoimmune diseases (\%) & $10(67 \%)$ \\
Familial aggregation $(\%)$ & $2(13 \%)$ \\
\hline
\end{tabular}

\section{Basal evaluation (before treatment)}

Before treatment with SSA, gastroscopy revealed macroscopic GC tumours (described as 'nodules', 'ulcers' or 'polyps') in all patients, with a mean diameter of $9.10 \pm 9.7 \mathrm{~mm}$ (mean \pm s.D.; range $5-40 \mathrm{~mm}$ ). The tumours were single in 4 out of 15 patients $(27 \%)$, and multiple (defined as $\geq 2$ tumours seen on gastroscopy) in the remaining 11 (73\%). ECL-cell hyperplasia was observed in all patients, while intestinal metaplasia was found in two. The mean Ki-67\% proliferation index was $4.4 \%$ (range $1-15 \%$ ). Apart from two patients (one patient with multiple tumours in whom one of the tumours invaded the adipose tissue and was surgically excised, and another patient with muscularis propria involvement; patient numbers 3 and 6 respectively; see Table 2), in all others the disease was limited to the stomach, without involvement of the muscularis propria, and no extra-gastric extension to regional lymph nodes (on endoscopy) or distant metastases. Following endoscopic removal, EUS was performed in all patients to reveal any residual submucosal tumours.

Gastrin and $\operatorname{CgA}$ levels were elevated in all patients $898 \pm 418 \mathrm{mI} / \mathrm{l}$ for gastrin (normal range 40 $108 \mathrm{mU} / \mathrm{l}$ ) and $370 \pm 183 \mathrm{ng} / \mathrm{ml}$ for $\mathrm{CgA}$ (normal range $19.4-98.1 \mathrm{ng} / \mathrm{ml})$. No clear correlation was found between initial gastrin and $\mathrm{CgA}$ serum levels and the number or size of the tumours.

At diagnosis, OctreoScan was positive only in one patient in which the size of his biggest tumour was $4 \mathrm{~cm}$ and was surgically excised afterwards; the uptake was in concordance with the findings on both gastroscopy and EUS. None of the patients who underwent a CT scan of the abdomen was found to have a region of distant metastases.

\section{Follow-up assessment (after treatment with SSA)}

All patients tolerated treatment well and none discontinued treatment during a follow-up period of $17.8 \pm$ 7.47 months (mean \pm s.D). Apart from a slight perturbation in the control of pre-treatment diabetes mellitus in one patient (Table 2, patient 3), there were no other adverse effects associated with SSA treatment.

Thirteen patients $(87 \%)$ had symptoms attributed to atrophic gastritis (such as abdominal pain, nausea, vomiting or dyspepsia) that improved in all following treatment with SSA (using the described WHO criteria) (12). Serum gastrin was measured in all patients and decreased progressively in all except one patient from $898 \pm 418 \mathrm{mI} / \mathrm{l}$ pre-treatment, reaching $304 \pm$ $278 \mathrm{mI} / \mathrm{l}$ at last visit (normal range $40-108 \mathrm{mI} / \mathrm{l}$, $P<0.005$; Fig. 3A). In one patient, despite an initial positive response to treatment (in terms of a decrease in serum gastrin levels and tumour regression at endoscopy), an escape phenomenon was observed, as higher gastrin levels were found at the last examination besides 
Table 2 Clinical and histopathological characteristics of the study patients before and during somatostatin analogues (SSAs) treatment.

\begin{tabular}{|c|c|c|c|c|c|c|c|c|c|c|c|c|c|c|c|}
\hline \multicolumn{5}{|c|}{ Patients details } & \multicolumn{7}{|c|}{ Before treatment with SSA } & \multicolumn{4}{|c|}{ After treatment with SSA } \\
\hline $\mathrm{Nr}$ & $\begin{array}{c}\text { Age } \\
\text { (years) }\end{array}$ & Sex & $\mathrm{PA}$ & $\begin{array}{l}\text { SSA/monthly } \\
\text { dosage (mg) }\end{array}$ & $\begin{array}{c}\mathrm{CgA} \\
(\mathrm{ng} / \mathrm{ml}) \\
(19-98)\end{array}$ & $\begin{array}{c}\text { Gastrin } \\
(\mathrm{mU} / \mathrm{l}) \\
(40-108)\end{array}$ & $\begin{array}{c}\mathrm{Nr} . \\
\text { lesions }\end{array}$ & ECLH & $\begin{array}{l}\text { Size, largest } \\
(\mathrm{mm})\end{array}$ & Invasion & $\begin{array}{c}\mathrm{Ki67} \\
(\%)\end{array}$ & $\begin{array}{c}\mathrm{CgA} \\
(\mathrm{ng} / \mathrm{ml}) \\
(19-98)\end{array}$ & $\begin{array}{c}\text { Gastrin } \\
(\mathrm{mU} / \mathrm{l}) \\
(40-108)\end{array}$ & $\begin{array}{l}\text { Nr. lesions/ } \\
\text { size }\end{array}$ & ECLH \\
\hline 1 & 56 & M & + & SomA 90 & $\mathrm{Na}$ & 1811 & Multiple & + & 15 & No & 5 & $\mathrm{Na}$ & 125 & None & None \\
\hline 2 & 66 & $\mathrm{~F}$ & + & SanLAR 30 & $\mathrm{Na}$ & 1000 & Multiple & + & 15 & No & 1 & $\mathrm{Na}$ & 345 & None & None \\
\hline 3 & 46 & $\mathrm{~F}$ & + & SanLAR 30 & $\mathrm{Na}$ & 1000 & Multiple & + & 40 & Adipose tissue & 15 & $\mathrm{Na}$ & 122 & None & None \\
\hline 4 & 47 & $\mathrm{~F}$ & + & SanLAR 30 & $\mathrm{Na}$ & 1000 & Single & + & 11 & No & 1 & $\mathrm{Na}$ & 137 & None & None \\
\hline 5 & 61 & $\mathrm{~F}$ & + & SanLAR 30 & $\mathrm{Na}$ & 796 & Single & + & 5 & No & 3 & $\mathrm{Na}$ & 425 & None & None \\
\hline 6 & 61 & M & + & SanLAR 20 & $\mathrm{Na}$ & 123 & Multiple & + & 3 & $\begin{array}{c}\text { Muscularis } \\
\text { mucosa }\end{array}$ & 1 & $\mathrm{Na}$ & 53 & None & None \\
\hline 7 & 60 & $\mathrm{~F}$ & + & SanLAR 30 & $\mathrm{Na}$ & 1400 & Multiple & + & 3 & No & 2 & $\mathrm{Na}$ & 223 & None & None \\
\hline 8 & 43 & $\mathrm{~F}$ & + & SanLAR 20 & $\mathrm{Na}$ & 977 & Multiple & + & 4 & No & 2 & $\mathrm{Na}$ & 193 & Single, $1 \mathrm{~mm}$ & None \\
\hline 9 & 48 & $\mathrm{~F}$ & + & SanLAR 20 & $\mathrm{Na}$ & 806 & Multiple & + & 10 & No & 1 & $\mathrm{Na}$ & 132 & Single, $1 \mathrm{~mm}$ & None \\
\hline 10 & 60 & $\mathrm{~F}$ & + & SanLAR 20 & $\mathrm{Na}$ & 1200 & Multiple & + & 9 & No & 2 & $\mathrm{Na}$ & 225 & None & None \\
\hline 11 & 45 & $\mathrm{~F}$ & + & SanLAR 30 & 265 & 336 & Multiple & + & 6 & No & 3 & 192 & 32 & None & None \\
\hline 12 & 57 & $\mathrm{~F}$ & + & SanLAR 20 & 255 & 1000 & Multiple & + & 5 & No & 4 & 205 & 635 & None & None \\
\hline 13 & 67 & $\mathrm{~F}$ & + & SanLAR 20 & 532 & 1006 & Multiple & + & 8 & No & 2 & 198 & 538 & Single, $2 \mathrm{~mm}$ & None \\
\hline 14 & 51 & $\mathrm{~F}$ & + & SanLAR 30 & 197 & 860 & Single & + & 15 & No & 5 & 59 & 159 & None & None \\
\hline 15 & 40 & $\mathrm{~F}$ & + & SanLAR 30 & 600 & 461 & Single & + & 5 & No & 1 & 3470 & 681 & Single, $5 \mathrm{~mm}$ & + \\
\hline
\end{tabular}

In patient 15, after an initial good response to treatment, the tumour progressed, in association with elevation of gastrin and chromogranin A levels in the serum. PA, pernicious anaemia; Nr. of lesions, single $=$ on lesion seen on endoscopy, multiples $\geq 2$ lesions seen on endoscopy; ECLH, ECL-cell hyperplasia; SomA, Somatuline Autogel; SanLAR, Sandostatin LAR. 
treatment with SS analogues (Table 2, patient 15). The levels of serum $\mathrm{CgA}$ were consistently evaluated in five patients $(34 \%)$ and decreased significantly in all except one, from $370 \pm 183 \mathrm{ng} / \mathrm{ml}$ to $148 \pm$ $69.3 \mathrm{ng} / \mathrm{ml}$ (mean \pm s.D.; normal range 19.4 $98.1 \mathrm{ng} / \mathrm{ml}, P<0.005$; Fig. 3B).

In all patients, gastroscopic examination showed a reduction in the size and number of carcinoid tumours at 6 months of treatment. In 11 patients $(73 \%)$, a complete disappearance of the tumours at 1 year of treatment was observed (Figs 1 and 2). In three patients (20\%; Table 2, patients 8, 9 and 13), the tumours decreased significantly in number (from 'multiple' to 'single') and in size (from $7.33 \pm 3.06 \mathrm{~mm}$ to $1.33 \pm$ $0.57 \mathrm{~mm}$, mean \pm s.D.), without complete disappearance; in this small subgroup of patients, an important decrease in the number of cells positively staining for neuroendocrine markers was observed, in parallel with inhibition of Ki-67 proliferation index, which decreased from $2.33 \pm 1.15$ to $1.67 \pm 0.57$ (mean \pm s.D). In one patient (Table 2, patient 15), following initial response, the original tumour progressed, in association with elevation of serum gastrin and $\mathrm{CgA}$ levels, and he was referred for antrectomy and surgical excision of the tumour. Intestinal metaplasia regressed and disappeared in the two patients observed before treatment.

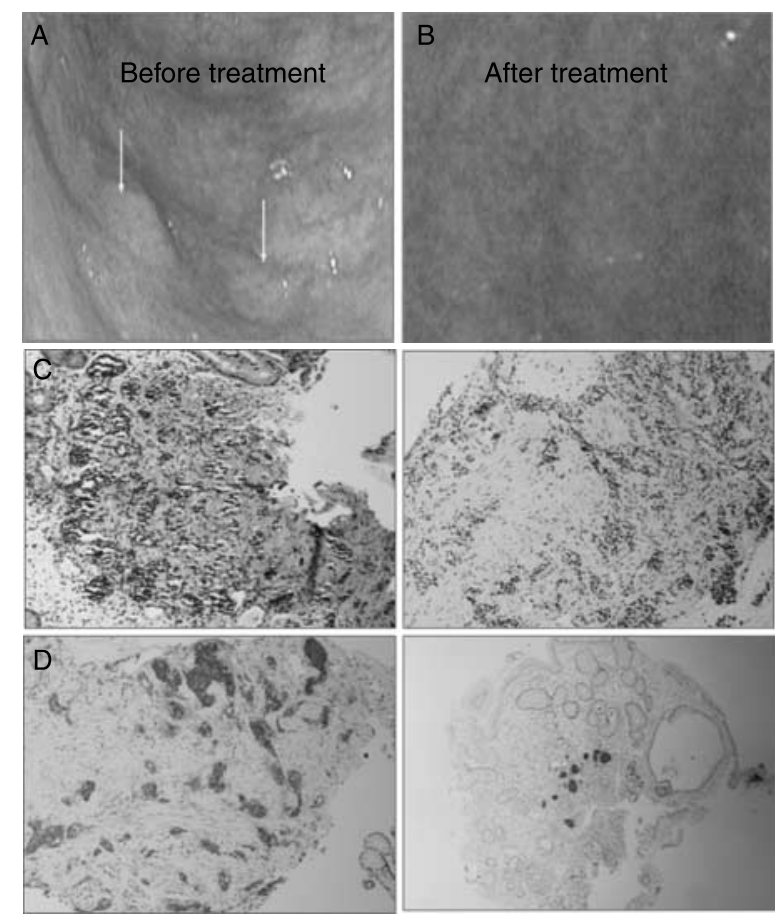

Figure 1 Gastroscopic appearance of gastric carcinoids before and after commencing treatment with somatostatin analogues in a 56-year-old male patient. (A) Multiple gastric carcinoids in the fundus area of the stomach before treatment. (B). Resolution of these tumours after 6 months of treatment. (C and D) Tumour regression is observed on biopsy, as well as a decrease in the cells immunostaining for synaptophysin (right panels).

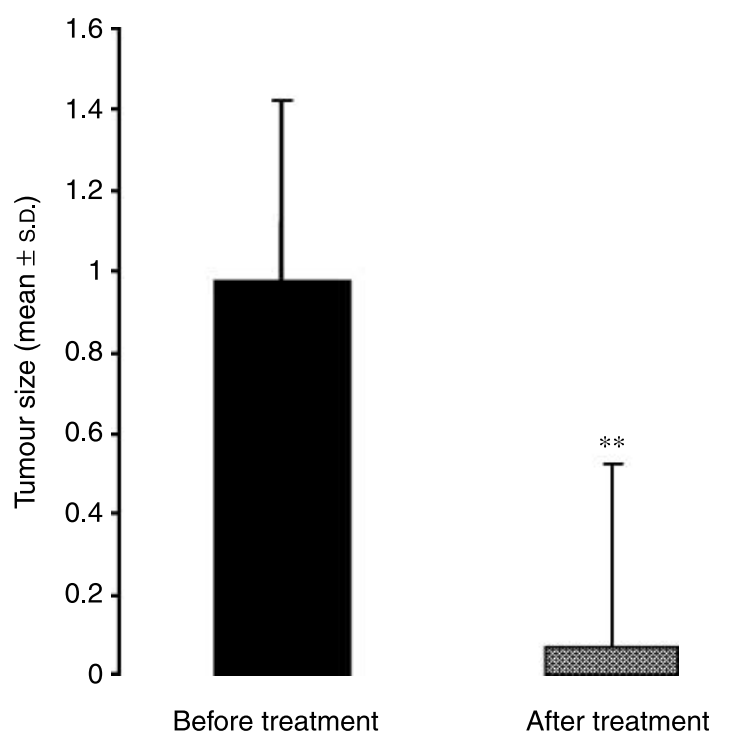

Figure 2 In all patients, gastroscopic examination showed a reduction in the size and number of the carcinoid tumours after 6 months of treatment $(P<0.05)$; it is important to emphasize that the analysis on the study-drugs effect on tumour size included all the tumours present after the excision of the 'dominant' lesion during the first gastroscopy.

All patients are still treated with SSA in an effort to determine the optimal duration of treatment in terms of gastrin and $\operatorname{CgA}$ suppression and tumour regression (Fig. 3).

\section{Discussion}

Despite the relatively 'benign' and indolent biological behaviour of GCA1 tumours, some may produce nonspecific symptoms, whereas $\sim 8-23 \%$ may metastasize to regional lymph nodes and rarely to the liver albeit with a low overall mortality (5). Although biotherapy with SSA is not currently recommended according to the European Neuroendocrine Tumours Society (ENETS) guidelines, it has been occasionally used in reference centres (26). The combination of octreotide and $\alpha$-interferon has been found to be of value in a patient with metastatic disease to the liver (5), whereas several, mainly small-sized studies, have documented a beneficial effect of treatment with SSA (26-29). The results of our study confirm these findings and show that treatment with long-acting SSA given at monthly intervals for a period of at least 6 months produces a significant suppression in gastrin and $\mathrm{CgA}$ levels, albeit without achieving complete normalization. Despite this apparently incomplete antisecretory effect, a significant anti-tumour effect is obtained, as shown from the regression of ECL-cell hyperplasia and tumour disappearance in the great majority of patients. This finding suggests a direct effect of these drugs on tumour cell proliferation. However, as the reported 5-year survival 

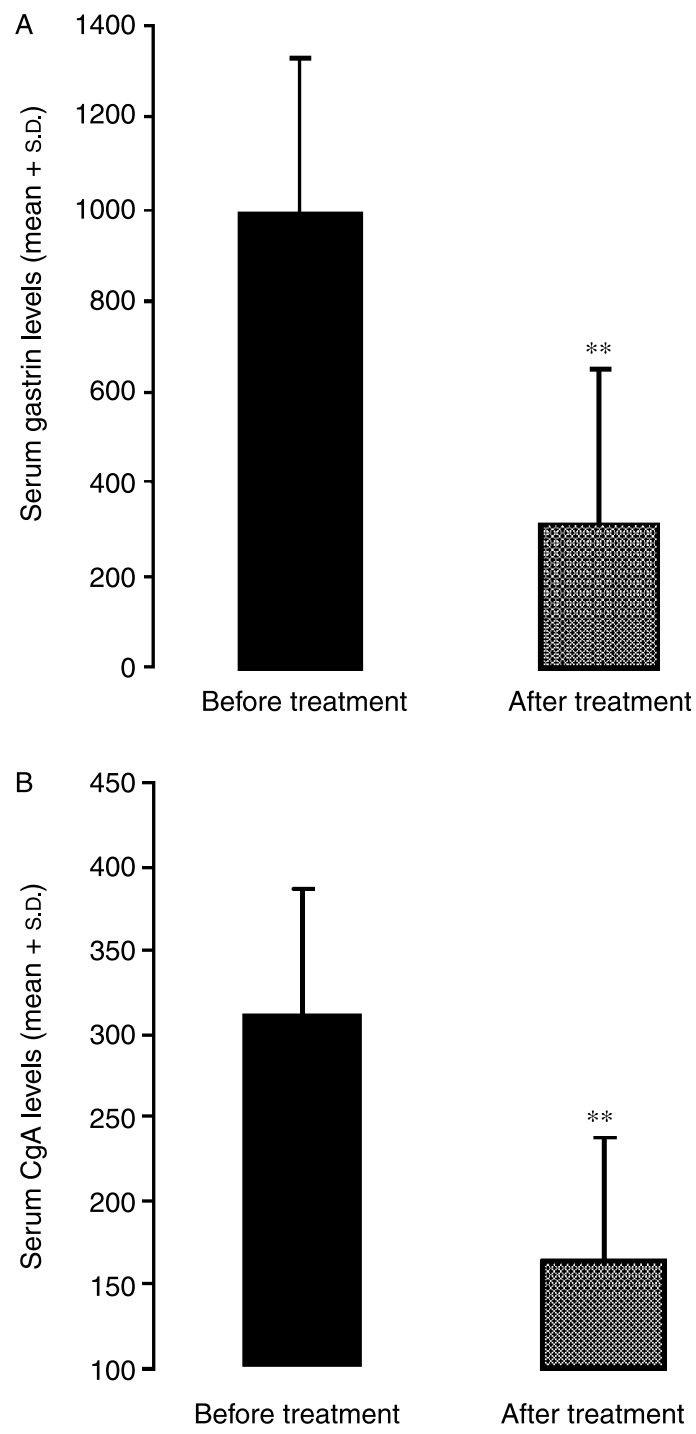

Figure 3 Plasma levels of gastrin and chromogranin $A$ before and at last follow-up in the patients included in the study. (A) Mean \pm S.D. serum gastrin levels decreased from $898 \pm 418 \mathrm{ml} / \mathrm{l}$ to $304 \pm$ $278 \mathrm{ml} / \mathrm{l}$ (normal range 40-108 ml/l; $P<0.005$ ). (B) The levels of serum $\mathrm{CgA}$, evaluated in 5 out of 15 patients, decreased from $370 \pm$ $183 \mathrm{ng} / \mathrm{ml}$ to $148 \pm 69.3 \mathrm{ng} / \mathrm{ml}$ (mean \pm s.D.; normal range $19.4-$ $98.1 \mathrm{ng} / \mathrm{ml}, P<0.005)$.

of GCA1 patients is good particularly when followed regularly with endoscopy (30), and rarely spontaneous tumour regression may occur (31), the results of our study, and other similar studies should be considered on an individual patient basis.

In patients with CGA1 (type 1 ECLomas), annual surveillance is thought to be sufficient for patients harbouring tumours less than $10 \mathrm{~mm}$ (32). In the case of larger tumours, endoscopic resection is recommended for up to six polyps not involving the muscularis, whereas in the remaining patients, local surgical tumour resection should be performed (30). However, the validity of such an approach is based on the findings of a single study (30). In addition, no strict guidelines are available for patients with tumours greater than $1 \mathrm{~cm}$ in size, when the risk of malignancy may be increased, and for those whose tumours recur despite repeated excisions (32). Antral resection, which is thought to diminish repeated and chronic gastrin stimulation of ECL cells, is effective in $80 \%$ of type 1 tumours (33-35). Antrectomy and local resection is also performed in the presence of deep gastric parietal wall invasion and positive margins following endoscopic removal (36). Partial or total gastrectomy with lymph node dissection is employed in the presence of malignancy or recurrence besides local surgical resection (36).

The rationale of using SSA in patients with GCA1 resides in the notion that the lack of gastrin's stimulatory effect on ECL cells may lead to regression of hyperplastic and/or dysplastic lesions (1). This is also the case when patients with GCA1 undergo an antrectomy thus removing the source of excessive gastrin secretion. However, such an approach is not always successful, as cases of recurrence of CGA1 after antrectomy have described $(37,38)$. This could be attributed to established and evolving changes in the genome of remaining ECL cells that undergo autonomous proliferation besides lack of gastrin stimulation. The use of SSA, apart from a reduction in gastrin hypersecretion, may also exert an anti-proliferative effect in the hyperplastic or dysplastic ECL cells. This approach is not associated with the complications of a relatively extensive surgery, such as antrectomy, and offers the opportunity of a medically induced reduction of the size and/or the number of the ECLomas. In addition, most ECLomas are preceded (or accompanied) by linear or micronodular hyperplasia or dysplasia of ECL cells (39). This condition is associated with a 26-fold increase in the risk of developing ECLomas in patients with chronic gastritis (40). As shown from the results of our study, SSA can also affect these changes therefore substantially reducing the risk of further lesion development. Intestinal metaplasia, which may also arise in the context of long-lasting chronic atrophic gastritis and may precede the development of gastric adenocarcinoma (41-43), was totally suppressed by treatment with SSA in the present study.

Information regarding the use of SSA in the treatment of CGA1 is rather scanty. Following the disappearance of GCA2 after s.c. octreotide administration (29), the long-acting SSA octreotide-LAR induced a permanent regression and disappearance of multiple CGA1s with normalization of elevated serum gastrin in a patient treated for 9 months (28). Treatment with monthly injections of octreotide-LAR for 1 year was also assessed in five patients with hypergastrinaemia-induced GCs (27). At the end of the study, although gastrin levels did not totally normalize, a substantial reduction in the density of ECL cells and tumour load, accompanied with a concomitant reduction in $\mathrm{CgA}$ levels was noticed. These findings indicate a possible direct anti-proliferative effect of the 
treatment. Recently, nine patients with more than five type I gastric endocrine tumours each less than $1 \mathrm{~cm}$ in size, without invasion of the muscularis propria and a Ki-67 index lower than 3\%, were treated with longacting SSA; in all patients, the tumours disappeared after 12 months of therapy, in parallel with significant reduction of $\mathrm{CgA}$ and gastrin levels (26). However, it is still unclear why some patients fail to achieve normalization of serum gastrin and why a minority besides an initial biochemical and morphological response develop a rebound increase in gastrin levels, using the same dosage of the given drugs. This heterogeneous response of GCs to the administration of SSA suggests that the effects of these drugs probably include a combination of both a direct effect on the tumour and an indirect effect, on the gastrin-induced cellular hyperplasia.

Despite the complete disappearance of the tumours in the majority of patients included in the present study, in a small subgroup of three patients the tumours did not totally regress. This different tumour behaviour was not found to be related to higher levels of gastrin or $\mathrm{CgA}$. Still, in this small subgroup of limited responsive patients, in terms of partial reduction in the number and size of the tumours, and in their index of proliferation, treatment with SSA may induce an important tumour down staging (i.e. large tumours can become smaller and therefore removed endoscopically rather than proceeding to surgery).

The administration of SSA as a chronic therapeutic option in GCA1 patients could be limited by undesirable side-effects $(44,45)$, or by the high cost of these drugs; however, side-effects are mostly temporary, usually observed in a minority of patients, as demonstrated in our study. In order to address these potential limitations of treatment with SSA, a prospective study, including a control group (i.e. patients without treatment with SSA), is required. Such a study could be important as it could justify the use of SSA in particular groups of patients, such as older patients who may have other comorbidities and in whom surgical therapy, when indicated, may not be easily applicable and without significant risks, or patients that cannot be followed up regularly.

Based on the results of our study, SSA could be used as first-line treatment for hypergastrinaemia-associated GCs, replacing the conventional endoscopic or surgical excisions, particularly in patients with multiple or relapsing tumours. In these patients, treatment with SSA could be continued as long as gastrin/CgA levels are suppressed, in parallel with decrease/disappearance of the tumours observed on regular endoscopy. Moreover, surgical procedures should most probably be performed only in patients unresponsive to medical treatment.

\section{Declaration of interest}

The authors declare that there is no conflict of interest that would prejudice the impartiality of this scientific work.

\section{References}

1 Gough DB, Thompson GB, Crotty TB, Donohue JH, Kvols LK, Carney JA, Grant CS \& Nagorney DM. Diverse clinical and pathologic features of gastric carcinoid and the relevance of hypergastrinemia. World Journal of Surgery 199418 473-479.

2 Kulke MH \& Mayer RJ. Carcinoid tumors. New England Journal of Medicine 1999340 858-868.

3 Rindi G, Azzoni C, La Rosa S, Klersy C, Paolotti D, Rappel S, Stolte M, Capella C, Bordi C \& Solcia E. ECL cell tumor and poorly differentiated endocrine carcinoma of the stomach: prognostic evaluation by pathological analysis. Gastroenterology 1999116 532-542.

4 Soga J. Gastric carcinoids: a statistical evaluation of 1,094 cases collected from the literature. Surgery Today 199727 892-901.

5 Granberg D, Wilander E, Stridsberg M, Granerus G, Skogseid B \& Oberg K. Clinical symptoms, hormone profiles, treatment, and prognosis in patients with gastric carcinoids. Gut 199843 223-228.

6 Borch K, Renvall H \& Liedberg G. Gastric endocrine cell hyperplasia and carcinoid tumors in pernicious anemia. Gastroenterology $1985 \mathbf{8 8}$ 638-648.

7 Ahlman H, Dahlstrom A, Enerback L, Granerus G, Nilsson O, Persson S \& Tisell LE. Two cases of gastric carcinoids: diagnostic and therapeutic aspects. World Journal of Surgery 198812 356-361.

8 Kolby L, Wangberg B, Ahlman H, Jansson S, Forssell-Aronsson E, Erickson JD \& Nilsson O. Gastric carcinoid with histamine production, histamine transporter and expression of somatostatin receptors. Digestion 199859 160-166.

9 Modlin IM, Gilligan CJ, Lawton GP, Tang LH, West AB \& Darr U. Gastric carcinoids. The Yale experience. Archives of Surgery 1995 $130250-255$.

10 Thomas RM, Baybick JH, Elsayed AM \& Sobin LH. Gastric carcinoids. An immunohistochemical and clinicopathologic study of 104 patients. Cancer 199473 2053-2058.

11 Plockinger U, Rindi G, Arnold R, Eriksson B, Krenning EP, de Herder WW, Goede A, Caplin M, Oberg K, Reubi JC, Nilsson O, Delle FG, Ruszniewski P, Ahlman H \& Wiedenmann B. Guidelines for the diagnosis and treatment of neuroendocrine gastrointestinal tumours. A consensus statement on behalf of the European Neuroendocrine Tumour Society (ENETS). Neuroendocrinology $200480394-424$.

12 Rindi G, de Herder WW, O'Toole D \& Wiedenmann B. Consensus guidelines for the management of patients with digestive neuroendocrine tumors: the second event and some final considerations. Neuroendocrinology $2008 \mathbf{8 7} 5-7$.

13 Kapadia CR. Gastric atrophy, metaplasia, and dysplasia: a clinical perspective. Journal of Clinical Gastroenterology 200336 S29-S36.

14 Gilligan CJ, Lawton GP, Tang LH, West AB \& Modlin IM. Gastric carcinoid tumors: the biology and therapy of an enigmatic and controversial lesion. American Journal of Gastroenterology 199590 338-352.

15 Norton JA, Melcher ML, GibrilF \& Jensen RT. Gastric carcinoid tumors in multiple endocrine neoplasia-1 patients with Zollinger-Ellison syndrome can be symptomatic, demonstrate aggressive growth, and require surgical treatment. Surgery 2004136 1267-1274.

16 Kulke MH. Clinical presentation and management of carcinoid tumors. Hematology/Oncology Clinics of North America 200721 433-455.

17 Tomassetti P, Campana D, Piscitelli L, Mazzotta E, Brocchi E, Pezzilli R \& Corinaldesi R. Treatment of Zollinger-Ellison syndrome. World Journal of Gastroenterology 200511 5423-5432.

18 Wangberg B, Grimelius L, Granerus G, Conradi N, Jansson S \& Ahlman $\mathrm{H}$. The role of gastric resection in the management of multicentric argyrophil gastric carcinoids. Surgery $1990 \mathbf{1 0 8}$ $851-857$.

19 D’Adda T, Annibale B, Delle FG \& Bordi C. Oxyntic endocrine cells of hypergastrinaemic patients. Differential response to antrectomy or octreotide. Gut $199638668-674$.

20 Delle FG \& Annibale B. Modulation of growth of human gastric enterochromaffin-like cells. Digestion 199657 (Supplement 1) $15-16$. 
21 Higham AD, Dimaline R, Varro A, Attwood S, Armstrong G, Dockray GJ \& Thompson DG. Octreotide suppression test predicts beneficial outcome from antrectomy in a patient with gastric carcinoid tumor. Gastroenterology $1998114817-822$.

22 Modlin IM, Lawton GP, Miu K, Kidd M, Luque EA, Sandor A \& Tang LH. Pathophysiology of the fundic enterochromaffin-like (ECL) cell and gastric carcinoid tumours. Annals of the Royal College of Surgeons of England $1996 \mathbf{7 8} 133-138$.

23 Bordi C, Azzoni C, Pilato FP, Robutti F, D’Ambra G, Caruana P, Rindi G, Corleto VD, Annibale B \& Delle FG. Morphometry of gastric endocrine cells in hypergastrinemic patients treated with the somatostatin analogue octreotide. Regulatory Peptides 199347 307-318.

24 Grozinsky-Glasberg S, Grossman AB \& Korbonits M. The role of somatostatin analogues in the treatment of neuroendocrine tumours. Molecular and Cellular Endocrinology $2008286238-250$.

25 Rindi G, Kloppel G, Alhman H, Caplin M, Couvelard A, de Herder WW, Erikssson B, Falchetti A, Falconi M, Komminoth P, Korner M, Lopes JM, McNicol AM, Nilsson O, Perren A, Scarpa A, Scoazec JY \& Wiedenmann B. TNM staging of foregut (neuro)endocrine tumors: a consensus proposal including a grading system. Virchows Archiv $2006 \mathbf{4 4 9} 395-401$.

26 Campana D, Nori F, Pezzilli R, Piscitelli L, Santini D, Brocchi E, Corinaldesi R \& Tomassetti P. Gastric endocrine tumors type I: treatment with long-acting somatostatin analogs. EndocrineRelated Cancer, 2008 337-342 (DOI: 10.1677/ERC-07-0251).

27 Fykse V, Sandvik AK, Qvigstad G, Falkmer SE, Syversen U \& Waldum HL. Treatment of ECL cell carcinoids with octreotide LAR. Scandinavian Journal of Gastroenterology $200439621-628$.

28 Prommegger R, Bale R, Ensinger C, Sauper T, Profanter C, Knoflach M \& Moncayo R. Gastric carcinoid type I tumour: new diagnostic and therapeutic method. European Journal of Gastroenterology and Hepatology 200315 705-707.

29 Tomassetti P, Migliori M, Caletti GC, Fusaroli P, Corinaldesi R \& Gullo L. Treatment of type II gastric carcinoid tumors with somatostatin analogues. New England Journal of Medicine 2000 $343551-554$

30 Borch K, Ahren B, Ahlman H, Falkmer S, Granerus G \& Grimelius L. Gastric carcinoids: biologic behavior and prognosis after differentiated treatment in relation to type. Annals of Surgery 2005242 64-73.

31 Harvey RF. Spontaneous resolution of multifocal gastric enterochromaffin-like cell carcinoid tumours. Lancet 19881821.

32 de Herder WW, O'Toole D, Rindi G \& Wiedenmann B. ENETS Consensus Guidelines for the management of patients with digestive neuroendocrine tumors, part 1-stomach, duodenum and pancreas. Neuroendocrinology 200684 151-216.

33 Eckhauser FE, Lloyd RV, Thompson NW, Raper SE \& Vinik AI. Antrectomy for multicentric, argyrophil gastric carcinoids: a preliminary report. Surgery $1988 \mathbf{1 0 4} 1046-1053$.
34 Hirschowitz BI, Griffith J, Pellegrin D \& Cummings OW. Rapid regression of enterochromaffinlike cell gastric carcinoids in pernicious anemia after antrectomy. Gastroenterology 1992102 1409-1418.

35 Kern SE, Yardley JH, Lazenby AJ, Boitnott JK, Yang VW, Bayless TM \& Sitzmann JV. Reversal by antrectomy of endocrine cell hyperplasia in the gastric body in pernicious anemia: a morphometric study. Modern Pathology 19903 561-566.

36 Ruszniewski P, Delle FG, Cadiot G, Komminoth P, Chung D, KosKudla B, Kianmanesh R, Hochhauser D, Arnold R, Ahlman H, Pauwels S, Kwekkeboom DJ \& Rindi G. Well-differentiated gastric tumors/carcinomas. Neuroendocrinology 200684 158-164.

37 de Bree E, Papadimitraki E, Skordilis P \& Tsiftsis DD. Multiple gastric carcinoids. Journal of the American College of Surgeons 2004 199517.

38 Guillem P. Gastric carcinoid tumours. Is there a place for antrectomy? Annales de Chirurgie 2005130 323-326.

39 Annibale B, Azzoni C, Corleto VD, di Giulio E, Caruana P, D'Ambra G, Bordi C \& Delle FG. Atrophic body gastritis patients with enterochromaffin-like cell dysplasia are at increased risk for the development of type I gastric carcinoid. European Journal of Gastroenterology and Hepatology 200113 1449-1456.

40 Solcia E, Fiocca R, Villani L, Luinetti O \& Capella C. Hyperplastic, dysplastic, and neoplastic enterochromaffin-like-cell proliferations of the gastric mucosa. Classification and histogenesis. American Journal of Surgical Pathology 199519 S1-S7.

41 Kokkola A, Haapiainen R, Laxen F, Puolakkainen P, Kivilaakso E, Virtamo J \& Sipponen P. Risk of gastric carcinoma in patients with mucosal dysplasia associated with atrophic gastritis: a follow up study. Journal of Clinical Pathology 1996 49 979-984.

42 Kokkola A, Sjoblom SM, Haapiainen R, Sipponen P, Puolakkainen P \& Jarvinen $\mathrm{H}$. The risk of gastric carcinoma and carcinoid tumours in patients with pernicious anaemia. A prospective follow-up study. Scandinavian Journal of Gastroenterology 199833 88-92.

43 Siurala M \& Seppala K. Atrophic gastritis as a possible precursor of gastric carcinoma and pernicious anemia. Results of follow-up examinations. Acta Medica Scandinavica 1960166 455-474.

44 Arnold R, Simon B \& Wied M. Treatment of neuroendocrine GEP tumours with somatostatin analogues: a review. Digestion 2000 62 (Supplement 1) 84-91.

45 Ayuk J, Stewart SE, Stewart PM \& Sheppard MC. Long-term safety and efficacy of depot long-acting somatostatin analogs for the treatment of acromegaly. Journal of Clinical Endocrinology and Metabolism $2002874142-4146$.

Received 17 July 2008

Accepted 24 July 2008 